\title{
Examining the spatial variations of co- morbidity among young children in Ethiopia
}

\author{
Kasahun Takele ${ }^{1^{*}} \mathbb{D}$, Temesgen Zewotir ${ }^{2}$ and Denis Ndanguza ${ }^{3}$
}

\begin{abstract}
Background: Addressing the issues of childhood comorbidity remains a crucial global public health issue due to its consequences in child wellbeing. This study aims to account for nonlinear, spatial effect and to evaluate spatial variation in childhood co-morbidity at cluster level while controlling for important risk factors.

Methods: Using the 2016 Ethiopia DHS data, a multinomial logistic model was assessed by linear, nonlinear and random effects. The study also employed a spatial analysis tool which is Getis-Ord to identify hotspot areas of child comorbidity at the cluster level. The model with fixed, nonlinear and spatial effects identified as the best model to identify risk factors related to the coexistence of childhood illnesses.

Results: The results indicated that statistically significant high hotspots of comorbidity were found in Tigray and Oromia whereas low hotspots were found in Harari and Somali regions. Children between 10 and 15 months old were at high risk of co-morbidity in Ethiopia. Besides, our findings revealed that being male children, not-breastfed children, from households lack of toilet facility, children from households who use spring water, children born first, children from working mother, anemic children and children from uneducated mother are at high risk of multiple illnesses.

Conclusions: Comorbidity in childhood is not random in the country, with high hotspots of comorbidity in the regions of Tigray and Oromia. The results show a critical upshot for a combined morbidity control method for decreasing children's illnesses and death. The maps remain novel to design appropriate healthcare interventions at regional as well as cluster level. Regions with high hotspots of child comorbidity should be considered for health healthcare interventions.
\end{abstract}

Keywords: Child, Cough, Diarrhea, Fever, Multinomial

\section{Background}

Addressing the issues of childhood morbidity is a priority for the public health agenda since it remains the burden of child wellbeing specifically in developing countries. In sub-Saharan Africa, the foremost causes of childhood morbidity and mortality are diarrhea, cough and fever [1].

\footnotetext{
* Correspondence: kastake10@gmail.com

'African Center of Excellence in Data Science, University of Rwanda, Kigali, Rwanda

Full list of author information is available at the end of the article
}

In spite of improvements in fighting childhood illnesses, communicable diseases remain a foremost reason of death for children. For instance, diarrhea (8\%), pneumonia (15\%) and malaria (5\%) account for global children's death. In 2018, in Sub-Saharan Africa, one in thirteen children dies before his/her fifth birthday, which is sixteen times higher than the average ratio of one in one hundred ninety-nine in high-income countries [2]. Illnesses are unlikely to be uniformly distributed in a population, having income and regional disparities. Moreover, children might

(c) The Author(s). 2020 Open Access This article is licensed under a Creative Commons Attribution 4.0 International License, which permits use, sharing, adaptation, distribution and reproduction in any medium or format, as long as you give appropriate credit to the original author(s) and the source, provide a link to the Creative Commons licence, and indicate if changes were made. The images or other third party material in this article are included in the article's Creative Commons licence, unless indicated otherwise in a credit line to the material. If material is not included in the article's Creative Commons licence and your intended use is not permitted by statutory regulation or exceeds the permitted use, you will need to obtain permission directly from the copyright holder. To view a copy of this licence, visit http://creativecommons.org/licenses/by/4.0/ The Creative Commons Public Domain Dedication waiver (http://creativecommons.org/publicdomain/zero/1.0/) applies to the data made available in this article, unless otherwise stated in a credit line to the data. 
experience compound illnesses simultaneously or repeatedly, increasing the risk of severe disease or death [3].

Likewise, in Ethiopia, children's illness and death persist high because of the problem related to predominant sicknesses such as diarrhea, malaria, fever and cough. In 2016, 12\% of under-age of five children had a diarrheal incident, $14 \%$ had a fever incident and $16 \%$ had a cough incident in the 2 weeks before the survey. Diarrhea contributes to 1 in 10 (13\%) child deaths in Ethiopia [4].This specifies that addressing the issue of childhood illness plays a fundamental role in addressing the issue of under-5 child mortality circuitously.

Furthermore, spatial location is a proxy of socioeconomic and environmental risk factors that affect childhood morbidity prevalence. For that reason, determinations to decrease the problem of childhood morbidities should examine the influence of spatial effect on child well-being. Some of the literature on childhood morbidities acknowledges as it has variation and varied geographically [5-7]. For instance, a study conducted in Egypt by [5] revealed that childhood morbidity has a geographically clustered pattern. In the previous study on diarrhea, unsafe water, wasting and unsafe sanitation were the foremost risk factors for diarrhea, accountable for $80.4 \%$ of diarrhea deaths in children below-5 years [8]. Furthermore, thus far, few studies in developing countries have examined the relations among child's health, spatial variation, demographic, socio-economic and the environment in the distinct societies for a particular disease at a time $[6,7,9-12]$. However, the disease outcomes (diarrhea, fever and cough) frequently coexist and may share intersecting risk factors. Consequently, segregated analyses possibly will fail to give a complete depiction of the epidemiology of the comorbidities at the population level. In addition, some of the risk factors like age of child and spatial effect may not have a linear effect on the coexistence of childhood morbidities.
On the other hand, no previous study has used a method for analyzing nonlinear and spatial effects related to the coexistence of childhood diseases in Ethiopia using the Bayesian framework. The extent to which nonlinear and spatial affects the comorbidities remains poorly understood, also little has been known about the multiple illnesses. Considering the coexistence of diarrhea, fever and cough are critical for policymakers to understand the occurrence of illnesses to design for appropriate healthcare interventions at the community level. Therefore, in this paper, we aim to apply the Bayesian multinomial logistic model to account for nonlinear, spatial effect and to evaluate spatial variation in childhood comorbidities of diarrhea, fever and cough while controlling for important risk factors.

\section{Methods}

\section{Data source}

We used data from the 2016 Ethiopia DHS. The survey has collected data on childhood and mother wellbeing conditions in the country every 5 years using 2-stage sampling, stratified by state and urban-rural areas. It provides national and regional level estimates of children and population health indicators. All childbearing age women (15-49 years) were suitable for interviews. Questions employed to determine current occurrences of the three morbidities were: "Does/Did the child had diarrhea/ fever/cough in the last two weeks?" Generally, 8742 data for diarrhea, fever and cough were collected [4]. Then the incidence of diarrhea/fever/cough considered as "Yes" or "No." Risk factors considered in the study were child's sex, child's age, region, breastfeeding, types of toilet facility, place of delivery, mother's work status, household size, mother's educational level, childbirth order and source of drinking water. Each observation linked to 11 regions, as the data were georeferenced and spatial analysis is reasonable. Selected risk factors of childhood comorbidity are shown in Fig. 1.

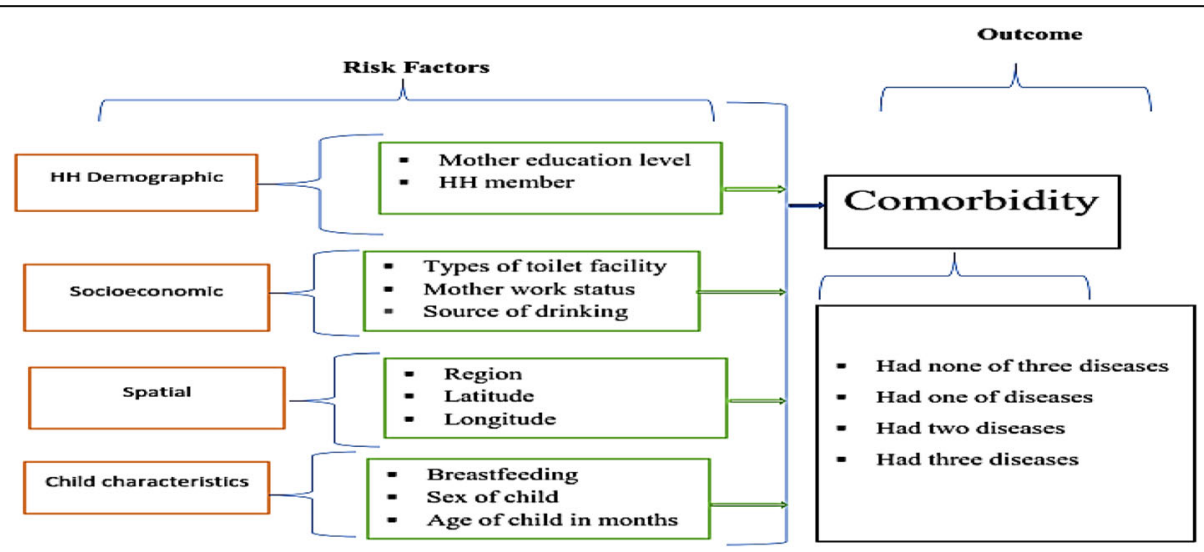

Fig. 1 Selected risk factors of childhood comorbidity 


\section{Statistical methods}

When studying childhood diseases, the intention is to associate the response variable "comorbidity" to socioeconomic, demographic, health and spatial covariates. Henceforth, from a statistical viewpoint, the outcome variable is given by a nominal categorical variable $\left(y_{i j l}\right)$ with unranked categories. Where $y_{i j l}$ be the sickness status and $\pi_{i j l}$ be the probability of multiple comorbidity of child $j, j=1, \ldots, n_{i}$ in region $i, i=1, \ldots, 11$. Then the comorbidity of a child is coded as:

$$
y_{i j l}=\left\{\begin{array}{l}
l=0 \text { had non of illnesses } \\
l=1 \text { had one illness } \\
l=2 \text { had two illnesses } \\
l=3 \text { had three illnesses }
\end{array}\right.
$$

Then, the most protuberant logistic model for this condition is the multinomial logit model $[9,13]$. Consequently, the distribution of $y_{i j l}$ is a multinomial i.e. $y_{i j l} \sim M\left(1, \pi_{i j l}\right)$, and $\pi_{i j l}=\left(\pi_{i j 0}, \pi_{i j 1}, \ldots, \pi_{i j 3)}\right.$. Given some categorical risk factors, $H_{i j}$, continuous variables, $U_{i j}$ and region specific random effect, $S_{i l}$, the likelihood of comorbidity can be modeled as:

$$
\pi_{i j l}=\frac{\exp \left(\eta_{i j l}\right)}{1+\sum_{i=1}^{l} \exp \left(\eta_{i j l}\right)}, l=0,1, \ldots, 3
$$

Where

$$
\eta_{i j l}=H_{i j} \beta_{l}+f_{l}\left(U_{i j}\right)+S_{i l}
$$

is a predictor. $\eta_{i j l}$ is a known response function with a logit link function, $\beta_{l}$ is the vector of the regression parameters for each illness status $l, f_{l}$ is a smooth function for the continuous risk factors and $S_{i l}$ are the spatial effects that further split up into a spatially structured (correlated) $\left(f_{\text {str }}\right)$ and an unstructured (uncorrelated) $\left(f_{\text {ustr }}\right)$ effects, that means, $S_{i l}=f_{\text {str }}+f_{\text {ustr }}$. We consider $\exp \left(\beta_{l}\right)$ as a relative odds ratio for interpretation. To estimate model parameters we employed the fully Bayesian method. In a Bayesian setting, functions, linear parameters and the variances are considered to be random variables and appropriate prior distributions are assigned to them. For the fixed effect parameters, we assume independent diffuse priors, that is, $\beta_{l} \propto$ const in the absence of prior knowledge $[13,14]$. Dispersed Gaussian priors also used as alternative. For the smooth functions $f_{l}$, we used Bayesian version of $\mathrm{P}$-spline, the prior suggested by Lang and Brezger [15]. Smooth functions are nonparametric function and the prior permits the function to be estimated as linear combinations of the basis function (B-spline). Thus, we obtain:

$$
f(x)=\sum_{t=1}^{m} \beta_{t} B_{t}(x)
$$

where $B_{t}(x)$ are basis functions and $\beta_{t}$ are vector of unknown regression coefficients. Furthermore, the vector of unknown regression coefficients $\left(\beta_{t}\right)$ are elucidated to conform to a second-order random walk

$$
\beta_{(t)}=2 \beta_{(t-1)}-\beta_{(t-2)}+\epsilon_{(t)}
$$

with Gaussian errors $\epsilon_{t} \sim N\left(0, \tau^{2}\right)$ and the diffuse priors $\beta_{(1)} \propto$ const and $\beta_{(2)} \propto$ const, for starting values. Where $\tau^{2}$ is used to control the smoothness of the $B$-spline function. Weakly informative inverse Gamma prior $\tau^{2} \sim I G(a$, $b)$ were assigned to estimate the variance $\left(\tau^{2}\right)$ jointly with the $B$-spline function.

For the spatial part, Markov random field priors are common in spatial statistics specifically for the spatially correlated effect $f_{\text {str }}[9,16,17]$. In addition, it indicates that the spatial neighborhood relationships provided that the two regions share a common boundary. Hence, a spatial extension of the random walk model provides the conditional spatially autoregressive condition $[6,18]$. The spatial smoothness prior is denoted by

$$
f_{s t r}(s) \mid f_{s t r}(r), r \neq l \sim N\left(\sum_{r \in \phi_{l}} f_{s t r}(r)\left|N_{s}, \tau_{s t r}^{2}\right| N_{s}\right)
$$

where $N_{s}$ is the number of neighborhood regions and $r \in \phi_{l}$ represents that region $r$ is a neighbor of regions $s$. The conditional mean of $f_{s t r}(r)$ is the average function evaluations of neighboring regions. Besides, $\tau^{2}$ str used to control the amount of spatial smoothness. For a spatially unstructured effect $f_{u s t r}$, a common assumption is that the parameters $f_{\text {ustr }}(S)$ are identically and independently distributed Gaussian. Then, it is denoted by

$$
f_{\text {unstr }}(s) / \tau_{\tau_{\text {unstr }}^{2}} \sim N\left(0, \tau_{\text {unstr }}^{2}\right)
$$

Flexibility and the degrees of smoothness of the tradeoff is controlled by the variance parameter $\tau^{2}$, str, unstr. Furthermore, the inverse Gamma hyper-prior $\tau^{2} \sim I G\left(a_{j}\right.$, $\left.b_{j}\right)$ is assigned to the variance $\tau^{2}$. Implies that for $\tau^{2}$ str and $\tau^{2}{ }_{\text {unstr }}$ we assume $\tau_{s t r}^{2} \sim I G\left(a_{s t r}, b_{s t r}\right)$ and $\tau^{2}{ }_{\text {unstr }}^{2} \sim-$ $G\left(a_{\text {unstr }}, b_{\text {unstr }}\right)$. Usual selections for the hyperparameters are $a=1$ and $b=0.005$ or $a=b=0.001$ [14]. Then, the probability density function expressed as

$$
p\left(\tau^{2}\right) \propto\left(\tau^{2}\right)^{-a_{j-1}} \exp \left(-b_{j} \mid \tau^{2}\right)
$$

Bayesian inference is based on posterior distributions and is carried out using MCMC simulation techniques so that samples are drawn from full conditionals of single parameters or block parameters given the rest. Let $\alpha$ 
denote the vector of all unknown parameters in the model (i.e. $\alpha=\left(f, f_{\text {spat }}\right)$ and $\tau$ represent the vector of all variance components. Then, under usual conditional independence assumptions, for the multinomial logit model, Bayesian inference can be based on the posterior given by

$$
\begin{aligned}
& p\left(\alpha \mid y_{i j l}\right) \propto \prod_{i=1}^{n} L_{i}\left(y_{i j l}, \eta_{i j l}\right) \\
& \prod_{j=1}^{p}\left\{p\left(\beta_{j} \mid \tau_{j}^{2}\right) p\left(\tau_{j}^{2}\right)\right\} \\
& p\left(f_{\text {str }} \mid \tau_{\text {str }}{ }^{2}\right) \\
& p\left(f_{\text {unstr }} \mid \tau_{\text {ustr }}{ }^{2}\right)
\end{aligned}
$$

where $\beta_{j}$ are the vectors of regression coefficients corresponding to the function $f_{j}$. The full conditionals for the parameter vectors $\beta_{1}, \ldots \beta_{p}$ as well as the full conditionals for $f_{s t r}, f_{\text {ustr }}$ and fixed effects parameters $\gamma_{j}$ have known distributions. The inverse gamma distributions are used for these variance components $\tau^{2}$, str, unstr and (over all variance parameter $\delta^{2}$ ) $[9,18]$. Thus, a Gibbs sampler can be used for MCMC simulation. BayesX 2.1 software version was used for the data analysis. Deviance Information Criterion (DIC) was used for model comparison.

\section{Results}

Exploratory Data Analysis

Table 1 indicates the distribution of childhood comorbidity and its related risk factors. The significance of the chi-square tests are indicated using the p-value. Results from cross-tabulation indicate that the sex of child, anemia level, breastfeeding, toilet facility place of deliv-

\begin{tabular}{|c|c|c|c|c|c|c|}
\hline \multirow[t]{2}{*}{ Covariates } & \multirow[t]{2}{*}{ Level } & \multicolumn{4}{|l|}{ Comorbidity N (\%) } & \multirow{2}{*}{$\begin{array}{l}P \text { - } \\
\text { value }\end{array}$} \\
\hline & & Had none of the three illnesses & Had one illness & Had two illnesses & Had three illnesses & \\
\hline \multirow[t]{2}{*}{ Sex of child } & Male & $3222(72.3)$ & $683(15.3)$ & $400(9.0)$ & $149(3.3)$ & \multirow[t]{2}{*}{0.011} \\
\hline & Female & $3173(74.0)$ & $579(13.5)$ & $394(9.2)$ & $142(3.3)$ & \\
\hline \multirow[t]{2}{*}{ Anemia level } & Anemic & $6216(73.0)$ & $1236(14.5)$ & $779(9.1)$ & $289(3.4)$ & \multirow[t]{2}{*}{0.040} \\
\hline & Non-anemic & $179(80.6)$ & $26(11.7)$ & $15(6.8)$ & $2(0.9)$ & \\
\hline \multirow[t]{2}{*}{ Breastfeeding } & No & $2114(73.2)$ & $432(15.0)$ & $261(9.0)$ & $80(2.8)$ & \multirow[t]{2}{*}{0.035} \\
\hline & Yes & $4281(73.1)$ & $830(14.2)$ & $533(9.1)$ & $211(3.6)$ & \\
\hline \multirow[t]{3}{*}{ Type of toilet facility } & flush toilet & $250(71.4)$ & $52(14.9)$ & $37(10.6)$ & $11(3.1)$ & \multirow[t]{3}{*}{0.050} \\
\hline & latrine & $3253(73.4)$ & $669(15.1)$ & $380(8.6)$ & $130(2.9)$ & \\
\hline & no facility & $2892(73.0)$ & $541(13.7)$ & $377(9.5)$ & $150(3.8)$ & \\
\hline \multirow[t]{2}{*}{ Place of delivery } & home & $4231(75.0)$ & $771(13.7)$ & $465(8.2)$ & $176(3.1)$ & \multirow[t]{2}{*}{0.000} \\
\hline & health center & $2164(69.8)$ & $491(15.8)$ & $329(10.6)$ & $115(3.7)$ & \\
\hline \multirow[t]{2}{*}{ Currently working } & No & $4680(74.1)$ & $891(14.1)$ & $552(8.7)$ & $189(3.0)$ & \multirow[t]{2}{*}{0.002} \\
\hline & Yes & $1715(70.6)$ & $371(15.3)$ & $242(10.0)$ & $102(4.2)$ & \\
\hline \multirow[t]{3}{*}{ Household members } & 1-5 members & $2747(71.3)$ & $610(15.8)$ & $361(9.4)$ & $136(3.5)$ & \multirow[t]{3}{*}{0.009} \\
\hline & 6-10 members & $3457(74.9)$ & $607(13.1)$ & 407 (8.8) & $146(3.2)$ & \\
\hline & above 10 members & $191(70.5)$ & 45 (16.6) & $26(9.6)$ & $9(3.3)$ & \\
\hline \multirow[t]{3}{*}{ Highest educational level } & No education & $4160(74.7)$ & $730(13.1)$ & $495(8.9)$ & $181(3.3)$ & \multirow[t]{3}{*}{0.000} \\
\hline & Primary & $1578(69.7)$ & $370(16.3)$ & $230(10.2)$ & $86(3.8)$ & \\
\hline & Secondary and higher & $657(72.0)$ & $162(17.8)$ & $69(7.6)$ & $24(2.6)$ & \\
\hline \multirow[t]{3}{*}{ Birth order number } & 1st order & $1203(69.7)$ & $303(17.6)$ & $160(9.3)$ & $60(3.5)$ & \multirow[t]{3}{*}{0.002} \\
\hline & 2-3rd order & $2071(73.8)$ & $391(13.9)$ & $262(9.3)$ & $83(3.0)$ & \\
\hline & 4th and above order & $3121(74.2)$ & $568(13.5)$ & $372(8.8)$ & $148(3.5)$ & \\
\hline \multirow[t]{4}{*}{ Source of drinking water } & piped & $848(70.1)$ & $204(16.9)$ & $122(10.1)$ & $36(3.0)$ & \multirow[t]{4}{*}{0.038} \\
\hline & public tap & $2943(73.9)$ & $549(13.8)$ & $366(9.2)$ & $123(3.1)$ & \\
\hline & protected spring & $510(73.7)$ & $85(12.3)$ & $66(9.5)$ & $31(4.5)$ & \\
\hline & other & 2094 (73.2) & $424(14.8)$ & $240(8.4)$ & $101(3.5)$ & \\
\hline
\end{tabular}
ery, family size, mother work status, mother educational

Table 1 Distribution of childhood comorbidity and its related selected risk factors 
level, childbirth order and source of drinking water are potential risk factors significantly associated with children comorbidity at 5\% level of significance. For instance, the prevalence of having two illnesses is higher among the female children while having one disease among the male children $(9.2,15.3 \%, p$-value $=0.011)$, respectively. The incidence of childhood comorbidity is high among anemic children than non-anemic children $(p$-value $=0.040)$. Besides, from Table 1 , the place of delivery is highly associated with comorbidity ( $p$-value $<0.000$ ). The prevalence of having one or more illnesses is higher among children delivered at home than children delivered at a health center/hospital (15.8, 10.6 and 3.7\%).

\section{Hotspot Analysis}

Figure 2 shows the spatial distribution of childhood comorbidity. Red colors indicate significant ( $p$-value $<0.05$ ) clusters of comorbidity areas, whereas, blue colors show significant coldspot areas. The regions of Tigray, Amhara, SNNPR, Gambella and Oromia were the hotspot regions in the country. Whereas, the regions of Harari, Benishangul-Gumuz and Somali were revealed as coldspot regions (Fig. 2 and Table 2).

\section{Model fit}

We fit and compare the following structured additive regression models to identify the best-fit model to the data and to examine factors related to the likelihood of comorbidity with diarrhea, fever and cough. The first model (M1) estimated fixed effects while the second model (M2) incorporates the nonlinear effect $f$ (child age) without structured and unstructured effects. The third model (M3) considers the structured and unstructured effects and the fourth model (M4) added fixed effects to the third model. The fifth model (M5) includes fixed effects, nonlinear and structured effects. Finally, the sixth model (M6) includes both unstructured and structured effects besides linear and nonlinear effects.

$$
\begin{aligned}
\mathrm{M} 1: \eta_{i j k}= & \beta_{0}+H_{i j} \beta_{k} \\
\mathrm{M} 2: \eta_{i j k}= & \beta_{0}+\mathrm{H}_{i j} \beta_{k}+f(\text { CAge }) \\
\mathrm{M} 3: \eta_{i j k}= & \beta_{0}+f_{\text {str }}(\text { region })+f_{\text {unstr }}(\text { region }) \\
\mathrm{M} 4: \eta_{i j k}= & \beta_{0}+H_{i j} \beta_{k}+f_{\text {str }}(\text { region }) \\
& +f_{\text {unstr }}(\text { region }) \\
\mathrm{M} 5: \eta_{i j k}= & \beta_{0}+H_{i j} \beta_{k}+f(\text { CAge }) \\
& +f_{\text {str }}(\text { region }) \\
\mathrm{M} 6: \eta_{i j k}= & \beta_{0}+H_{i j} \beta_{k}+f(\text { CAge }) \\
& +f_{\text {str }}(\text { region })+f_{\text {unstr }}(\text { region })
\end{aligned}
$$

From Table 3, based on the DIC, the first model M1 has $\mathrm{DIC}=14,594.047$, while the second model M2 gave a DIC of 14,401.84 suggesting that the combined effects of linear and nonlinear explained the risk of comorbidity better than a fixed effect only. The third model M3 includes structured and unstructured effects only model which shows improvement than model M1. Furthermore, we considered linear, structured and unstructured effects (M4) with DIC $=14,428.595$, which suggest the joint effects of linear, structured and unstructured, explained the risk of comorbidity better than M1 and M3. The fifth model M5 includes linear, nonlinear and spatial effect suggesting that the model best explain the risk of coexistence of diseases as compared to the other candidate models. The sixth model M6 includes both

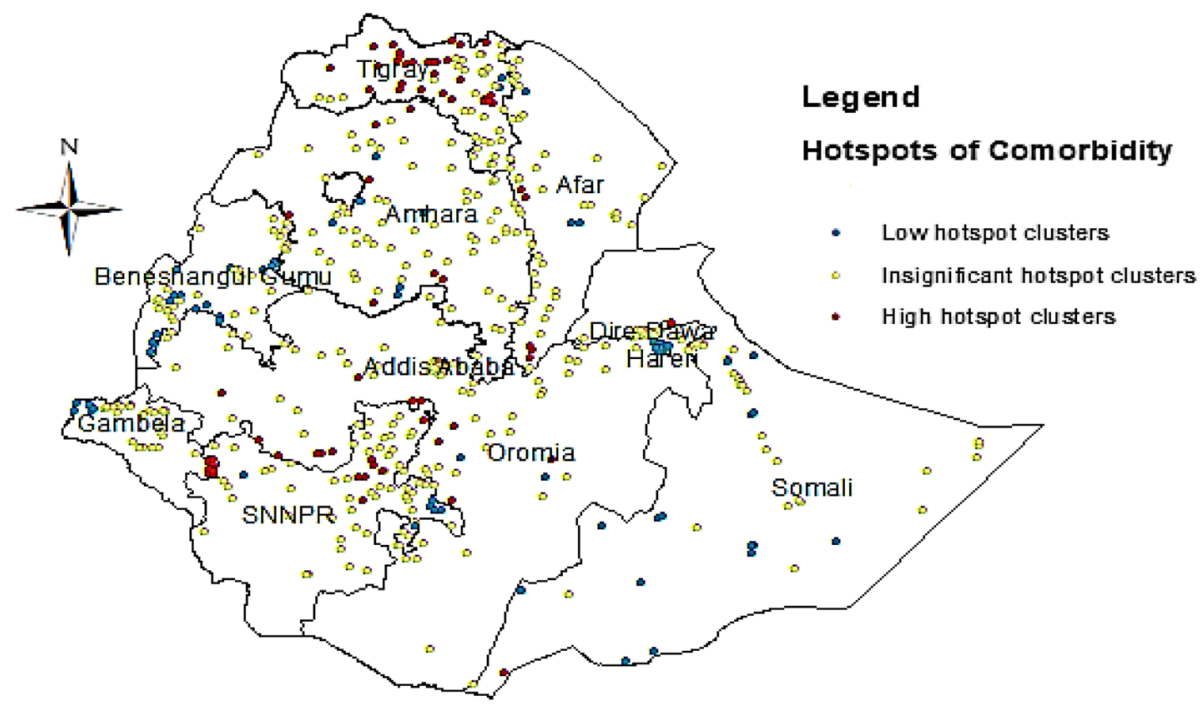

Fig. 2 Hotspot and coldspot identification of childhood comorbidity at cluster level. ArcGIS 10.5 software version was used to plot the map 
Table 2 Hotspot and coldspot analysis of childhood comorbidity between clusters

\begin{tabular}{lllll}
\hline Region & $\begin{array}{l}\text { Overall } \\
\text { clusters }\end{array}$ & $\begin{array}{l}\text { High } \\
\text { hotspots }\end{array}$ & $\begin{array}{l}\text { Low } \\
\text { hotspots }\end{array}$ & $\begin{array}{l}\text { Insignificant } \\
\text { hotspots }\end{array}$ \\
\hline Tigray & 63 & 29 & 2 & 32 \\
Afar & 53 & 5 & 3 & 45 \\
Amhara & 71 & 7 & 6 & 58 \\
Oromia & 74 & 13 & 2 & 59 \\
Somali & 67 & 1 & 14 & 52 \\
Benishangul & 50 & - & 17 & 37 \\
SNNPR & 71 & 7 & 6 & 58 \\
Gambela & 50 & 7 & 5 & 38 \\
Harari & 44 & - & 44 & - \\
Addis & 56 & - & - & 56 \\
Ababa & & & & 43 \\
Dire Dawa & 44 & 1 & - & \\
\hline
\end{tabular}

unstructured and structured effects besides linear and nonlinear effects. However, not shows improvement than M5. Hence, in this paper, we discuss the best model (M5).

\section{Fixed effects result from BGAMM}

Table 4 provides the posterior mean estimates of fixed effects of the demographic, socioeconomic and environmental related risk factors of comorbidity using the multinomial logistic regression model. The result presented in the table indicates $95 \%$ credible intervals. Whereas, when the $95 \%$ credible intervals include zero, it shows the effect is not statistically significant at 5\% level of significance. In addition, the table shows the estimated effects of categorical risk factors: child's sex, anemia level, breastfeeding, types of toilet facility, mother's work status, mother's educational level, childbirth order and source of drinking water on the comorbidity of diarrhea, cough and fever in Ethiopia. From Table 4, the result indicated that female children were at decreased risk of illness relative to male children (OR: 0.84; 95\% CI: 0.73, 0.95). Furthermore, from the same table, the odds of having combinations of the three

Table 3 Comparison of model fit using the Deviance Information Criterion (DIC)

\begin{tabular}{llll}
\hline Model & Deviance & PD & DIC \\
\hline M1 & $14,506.354$ & 43.84641 & $14,594.047$ \\
M2 & $14,276.435$ & 62.702432 & $14,401.84$ \\
M3 & $14,390.552$ & 30.632699 & $14,451.817$ \\
M4 & $14,292.931$ & 67.831814 & $14,428.595$ \\
M6 & $14,040.064$ & 86.639755 & $14,213.344$ \\
M5 & $14,041.291$ & 86.737705 & $14,214.766$ \\
\hline
\end{tabular}

illnesses (diarrhea, fever and cough) (OR: 0.23; 95\% CI: $0.04,0.85)$ were lower for non-anemic children relative to anemic children. Children breastfed were at decreased risk of comorbidity of diarrhea, fever and cough relative to non-breastfed children (OR: 0.77; 95\% CI: 0.67, 1.11, OR: 0.79, 95\% CI: 0.66, 0.95).

Similarly, there were a significant relationships between latrine toilet and flush toilet (OR: 0.38 ; $95 \% \mathrm{CI}$ : $0.18,0.91$ ) and (OR: 0.42; 95\% CI: 0.18, 0.99) with multiple illnesses, respectively. This means that children from households use latrine toilets were at decreased risk of diarrhea, fever and cough illnesses compared to children from households with no toilet facilities. The result also indicated that children from households with flush toilet facilities were at low risk of diarrhea, fever and cough illnesses relative to children from households with no toilet facilities. The other important risk factor associated with childhood comorbidity was the mother's current work status. Children from an employed mother were at high risk of comorbidity of diarrhea, fever and cough relative to children from unemployed mother (OR: 1.29; 95\% CI: 1.09, 1.55) and (OR: 1.66; 95\% CI: $1.29,2.20)$.

Furthermore, the results indicated that children from secondary and higher educated mother were at reduced risk of two illnesses compared to children from uneducated mother (OR: 0.56, 95\% CI: 0.41, 0.77). Additionally, childbirth order number is a significant risk factor for child illness. Children with birth order number higher were at decreased risk of comorbidity of diarrhea, fever and cough relative to the first birth order number. Household's source of drinking water is associated to childhood illnesses. Children from households drink protected spring (OR: 1.27, 95\% CI: 1.04, 1.55) were at high risk of two illnesses as compared to children from households drink piped water.

\section{Spatial effects}

Figure 3 (left) shows the multinomial estimated structured spatial effects of comorbidity. The result indicates a regional disparity in relative risk of a child exposed to a mixture of illnesses (diarrhea, fever and cough). From the map (left panel), the result shows the Northern and central regions of Ethiopia have high to medium prevalence (likelihood) of the only one illness. For instance, children residing in Tigray have the highest risk of having one of the diseases. Figure 3 (right panel) indicates the posterior probability maps of childhood comorbidity at a $95 \%$ credible interval. The regions in black shading are places where the estimates for specific illness were significantly lower, while the regions in white shading indicates places where the estimates for a specific illness were significantly higher. The regions in gray shading indicated an insignificant spatial effect on the child 
Table 4 Posterior mean estimates of fixed effect parameters for childhood comorbidity

\begin{tabular}{|c|c|c|c|}
\hline \multicolumn{4}{|c|}{ Posterior odds ratio (Cl: 95\%) } \\
\hline Factors & $\begin{array}{l}\text { Child had only } \\
\text { one illness }\end{array}$ & $\begin{array}{l}\text { Child had two } \\
\text { illnesses }\end{array}$ & $\begin{array}{l}\text { Child had three } \\
\text { illnesses }\end{array}$ \\
\hline Constant & $0.42(0.22,0.79)$ & $0.15(0.07,0.32)$ & $0.17(0.03,1.08)$ \\
\hline \multicolumn{4}{|c|}{ Sex of child (Male $=$ ref $)$} \\
\hline Female & $0.84(0.73,0.95)$ & $0.97(0.86,1.16)$ & $0.94(0.76,1.18)$ \\
\hline \multicolumn{4}{|c|}{ Anemia (Anemic $=$ ref) } \\
\hline Non anemic & $1.23(0.54,1.23)$ & $0.76(0.42,1.27)$ & $0.23(0.04,0.85)$ \\
\hline \multicolumn{4}{|c|}{ Breast $($ Yes $=$ No) } \\
\hline Yes & $0.77(0.67,0.89)$ & $0.79(0.65,0.95)$ & $0.89(0.68,1.18)$ \\
\hline \multicolumn{4}{|c|}{ Types of toilet (No toilet $=$ ref) } \\
\hline Latrine & $1.02(0.73,1.34)$ & $0.77(0.54,1.13)$ & $0.38(0.18,0.91)$ \\
\hline Flush toilet & $0.97(0.68,1.38)$ & $0.92(0.64,1.39)$ & $0.42(0.18,0.99)$ \\
\hline \multicolumn{4}{|c|}{ Place of delivery (Health center $=$ ref) } \\
\hline Home & $0.91(0.77,1.06)$ & $1.15(0.96,1.38)$ & $1.03(0.76,1.38)$ \\
\hline \multicolumn{4}{|c|}{ Working staus (no = ref) } \\
\hline Yes & $1.13(0.97,1.29)$ & $1.29(1.09,1.55)$ & $1.66(1.29,2.20)$ \\
\hline \multicolumn{4}{|c|}{ Household member (1-5) } \\
\hline $\begin{array}{l}\text { 6-10 } \\
\text { member }\end{array}$ & $0.72(0.53,1.03)$ & $0.96(0.63,1.40)$ & $0.63(0.37,1.02)$ \\
\hline $\begin{array}{l}\text { Above } 10 \\
\text { member }\end{array}$ & $0.69(3.25,1.42)$ & $1.19(0.44,2.75)$ & $0.72(0.14,2.48)$ \\
\hline \multicolumn{4}{|c|}{ Mother's Education (No education $=$ ref) } \\
\hline Primary & $0.84(0.71,0.79)$ & $1.00(0.83,1.21)$ & $1.15(0.86,1.58)$ \\
\hline $\begin{array}{l}\text { Secondary\& } \\
\text { higher }\end{array}$ & $1.13(0.89,1.43)$ & $0.56(0.41,0.78)$ & $0.76(0.45,1.27)$ \\
\hline \multicolumn{4}{|c|}{ Birth order (First order $=$ ref) } \\
\hline 2-3rd order & $0.79(0.69,0.94)$ & $0.98(0.79,1.22)$ & $0.98(0.59,1.65)$ \\
\hline $\begin{array}{l}\text { 4th and } \\
\text { above }\end{array}$ & $0.81(0.69,0.95)$ & $0.92(0.74,1.13)$ & $0.95(0.50,1.84)$ \\
\hline \multicolumn{4}{|c|}{$\begin{array}{l}\text { Source of drinking water (piped = } \\
\text { ref) }\end{array}$} \\
\hline Public tap & $0.99(0.89,1.13)$ & $1.06(0.92,1.25)$ & $0.94(0.63,1.40)$ \\
\hline $\begin{array}{l}\text { Protected } \\
\text { spring }\end{array}$ & $1.05(0.89,1.25)$ & $1.27(1.04,1.49)$ & $1.40(0.89,2.32)$ \\
\hline Other & $0.84(0.65,1.07)$ & $0.76(0.54,1.04)$ & $0.94(0.63,1.40)$ \\
\hline
\end{tabular}

morbidity. Results from the maps show that children from Benishangul-Gumuz and the eastern part of the country were less likely to have suffered from comorbidity of diarrhea, fever and cough (b, d and f). Whereas, children lives in regions of Tigray, Amhara and Oromia were more likely to have suffered from one of the illnesses (a). Similarly, children from regions of Oromia and Tigray were more likely to at high risk of comorbidity of diarrhea, fever, or cough (d). Moreover, children from regions of Tigray and SNNPR have higher likelihood of suffering from three illnesses (f).

\section{Nonlinear effect results from BGAMM}

The nonlinear effect components of the continuous covariate (child's age in months) are portrayed in Fig. 4. It indicates the posterior model estimates of a child's age together with $80 \%$ and $95 \%$ pointwise confidence intervals. The graphs are composed of five trend lines with the centerline is estimate of the posterior mean bounded by the two inner lines are $95 \%$ credible intervals and the outer lines are $80 \%$ credible intervals. Furthermore, the plots indicate a negative nonlinear effect of a child's age on the probability of the illnesses and their coexistences. The results show that children suffer from any of cough, diarrhea, or fever as they grow older to zenith around aged 10 to 15 months and it becomes decreases as the child grows in age (Fig. 4 (a-c). The Figure for each type of co-morbidity indicates that the child's health deteriorates quickly in 6-8 months. For instance, lower child age increases the risk of coexistence of diarrhea, fever and cough (Fig. 4 (c)).

\section{Discussion}

This study focused on cross-sectional data analysis of childhood comorbidities in Ethiopia using an application of spatial multinomial logistic models. It is believed that an understanding of the dynamics of the co-occurrence of illnesses is vital in evaluating the health conditions of a community. The study revealed that sex of child, anemia level, breastfeeding, types of toilet facility, mother's work status, source of drinking water, mother's educational level and childbirth order have a significant effect on comorbidities of childhood diseases in Ethiopia.

The result of the sex of the child confirms with the findings of $[5,12]$ where the sex of child effect on childhood illnesses was statistically significant. The result suggested that male children were more affected by one of the illnesses than female children. This situation is attributed to sex discernment and biological causes in [12]. Likewise, the results reveal that the risk of the three illnesses (diarrhea, fever and cough) was higher among non- breastfed children than breastfed children. The result supports the findings of $[6,10,19]$ as the notbreastfed children are in a worse relationship with infection. Moreover, the finding indicates that children from households that have no toilet facilities were associated with infection. Our finding is in agreement with previous studies $[10,12]$. As a result, this study suggests that interventions on household sanitation reduce risks to which a child exposed.

Similarly, our findings showed that children with employed mothers were at high risk of having comorbidities. This is maybe due to the employed mother leave her child at home with the hands of caretakers. Because of this, the length of breastfeeding shortened and caretakers 


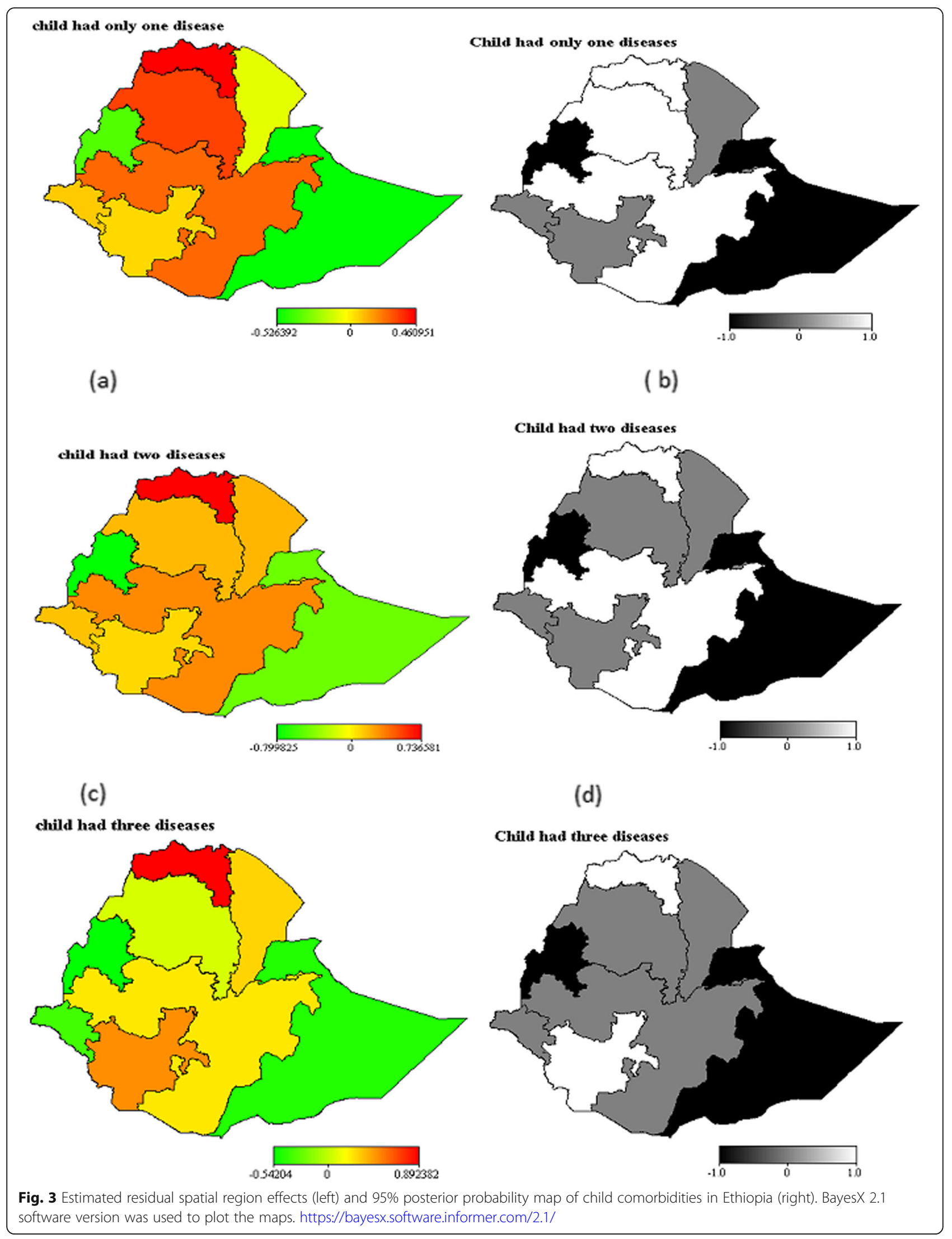




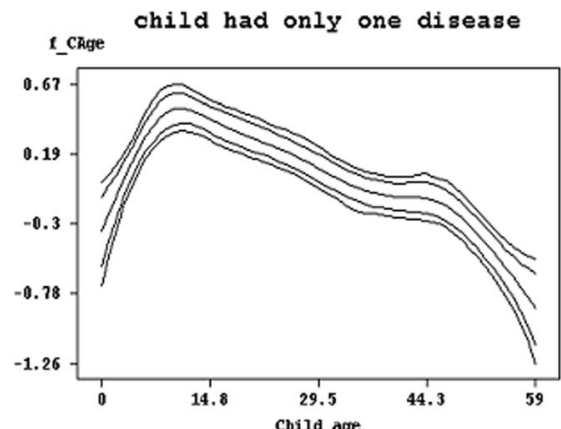

(a)

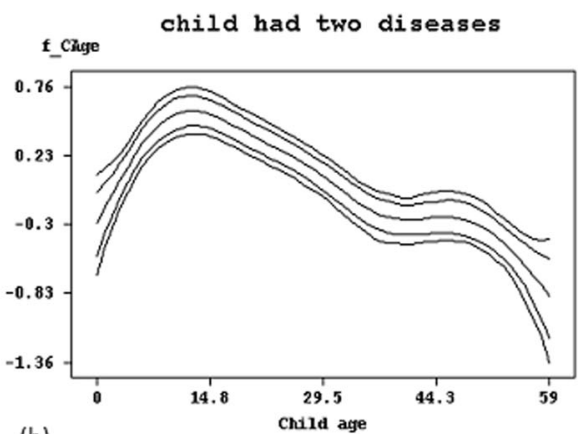

(b)

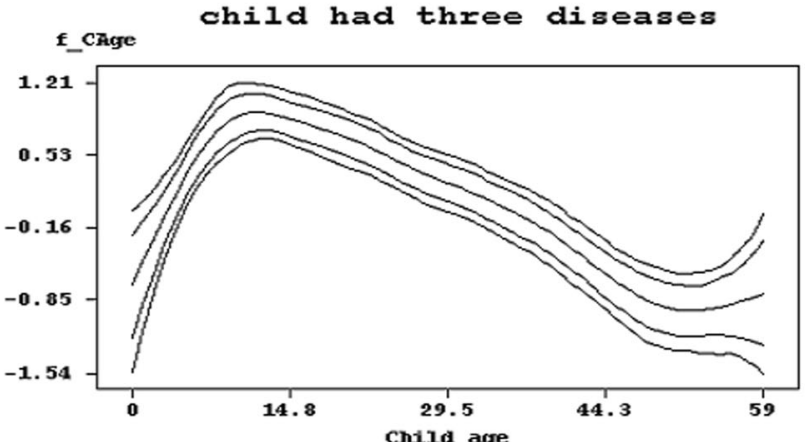

Fig. 4 Nonlinear effects of child's age (in months) on the comorbidity of diarrhea, fever and cough. BayesX 2.1 software version was used to plot the graphs. https://bayesx.software.informer.com/2.1/

are usually uneducated $[19,20]$. Also, the study found that the mother's education level is an important risk factor affecting the wellbeing of children in the country. Children from lower educated mothers are more at high risk of one of the illnesses and two illnesses. The finding is consistent with previous studies $[5,21]$. The other important focus of this study was to consider nonlinear effect components. The study result showed the negative nonlinear effect of the child's age on the odds of comorbidities. Likewise, a high risk of one of the illnesses and illness combinations observed among children aged around 10-15 months. The result is in agreement with that of [6]. Of specific notice here is that the analysis found that there is a regional disparity in relative risk of the combination of comorbidity of diarrhea, fever and cough in Ethiopia. Tigray, Amhara, SNNPR, Gambella and Oromia were identified as hotspots regions while Harari, Benishangul-Gumuz and Somali were identified as coldspot regions of illnesses. This is might be due to different factors like socioeconomic, geographical, political and cultural differences among the regions. Residual risk estimates ranged from -0.526 to 0.460 for a child who had only one illness, from -0.799 to 0.736 for a child who had two illnesses and from -0.542 to 0.893 for a child who had the illnesses comorbidities. Furthermore, the highest risk of the coexistence of cough, diarrhea and fever illnesses found in the Tigray region and SNNPR.

\section{Conclusions}

Diarrhea, cough, and fever are the foremost causes of childhood diseases and mortality in Ethiopia. The central intention in this study was to specify areas of hotspot and coldspot risk of childhood comorbidity of diarrhea, fever and cough in Ethiopia. This investigation identified significant disparities in childhood illnesses across the regions of the country and the effect played by demographic, socioeconomic and environmental factors. The results offered the likelihood of simultaneously observing problems of compound illnesses in Ethiopia. Our analysis identified that regions of Amhara, Oromia, SNNPR and Tigray have a high risk of comorbidity and are more pretentious. In addition, the findings revealed that being male children, from a household's lack of toilet facility, children from a family who use unsafe water, anemic children, children from working mothers, non-breastfed and children from uneducated mothers are at high risk of multiple illnesses. Younger children are at high risk of compound illness. Therefore, decision-makers should put more attention to targeting highly exposed regions as well as sociodemographic risk factors on childhood illness.

\section{Abbreviations}

DHS: Demographic and Health survey; BGAMM: Bayesian Geoadditive Multinomial Model 


\section{Acknowledgements}

We thank, ORC marco, measure DHS for providing us access to the data file.

\section{Availability of data and material}

The data can be accessed from http://www.dhsprogram.com/ by registering and requesting the datasets.

\section{Authors' contributions}

$\mathrm{KT}$ analyzed the data and produced a draft manuscript. TZ and DND commented on the write-up and improved the manuscript. All authors read and approved the final manuscript.

\section{Funding}

None.

\section{Ethics approval and consent to participate}

Not applicable.

\section{Consent for publication}

Not applicable.

\section{Competing interests}

The authors declare that they have no competing interests.

\section{Author details}

'African Center of Excellence in Data Science, University of Rwanda, Kigali, Rwanda. ${ }^{2}$ School of Mathematics, Statistics and Computer Sciences, University of KwaZulu-Natal, Durban, South Africa. ${ }^{3}$ College of Science and Technology, University of Rwanda, Kigali, Rwanda.

Received: 8 January 2020 Accepted: 11 June 2020

Published online: 19 June 2020

\section{References}

1. Kandala NB, Ji C, Stallard N, Stranges S, Cappuccio FP. Morbidity from diarrhoea, cough and fever among young children in Nigeria. Ann Trop Med Parasitol. 2008 Jul 1;102(5):427-45.

2. Hug L, Alexander M, You D, Alkema L. UIAG. National, regional, and global levels and trends in neonatal mortality between 1990 and 2017, with scenario-based projections to 2030: a systematic analysis. Lancet Glob Health. 2019;7(6):e710-20.

3. Richard SA, McCormick BJJ, Seidman JC, Rasmussen Z, Kosek MN, Rogawski ET, Petri W, et al. Relationships among common illness symptoms and the protective effect of breastfeeding in early childhood in MAL-ED: an eightcountry cohort study. Am J Trop Med Hygiene. 2018;98(3):904-12.

4. Ethiopia Demographic and Health Survey. Addis Ababa, and Rockville: ECSA and ICF; 2016.

5. Khatab K, Adegboye O, Mohammed TI. Social and demographic factors associated with morbidities in young children in Egypt: a Bayesian geoadditive semi-parametric multinomial model. PLoS One. 2016;11(7): e0159173.

6. Kandala NB, Ji C, Stallard N, Stranges S, Cappuccio FP. Spatial analysis of risk factors for childhood morbidity in Nigeria. Am J Trop Med hygiene. 2007; 77(4):770-9.

7. Tsiko RG. Bayesian spatial analysis of childhood diseases in Zimbabwe. BMC Public Health. 2015 Dec;15(1):842

8. Troeger C, Blacker B, Khalil IA, Rao PC, Cao J, Zimsen SR, Albertson SB, Deshpande A, Farag T, Abebe Z, Adetifa IM. Estimates of the global, regional, and national morbidity, mortality, and aetiologies of lower respiratory infections in 195 countries, 1990-2016: a systematic analysis for the global burden of disease study 2016. Lancet Infect Dis. 2018 Nov 1; 18(11):1191-210.

9. Kandala NB. Bayesian geo-additive modelling of childhood morbidity in Malawi. Appl Stoch Model Bus Ind. 2006 Mar;22(2):139-54.

10. Kazembe LN, Appleton CC, Kleinschmidt I. Choice of treatment for fever at household level in Malawi: examining spatial patterns. Malar J. 2007 Dec; 6(1):40.

11. Kazembe LN, Muula AS, Simoonga C. Joint spatial modelling of common morbidities of childhood fever and diarrhoea in Malawi. Health \& place. 2009 Mar 1;15(1):165-72.
12. Takele K, Zewotir T, Ndanguza D. Risk factors of morbidity among children under age five in Ethiopia. BMC Public Health. 2019 Dec;19(1):942.

13. Fahrmeir L, Tutz G. Multivariate statistical Modelling based on generalized linear models. New York: Springer-Verlag; 2001.

14. Fahrmeir L, Lang S. Bayesian semiparametric regression analysis of multicategorical time-space data. Ann Inst Stat Math. 2001 Mar 1;53(1):11-30.

15. Lang S, Brezger A. Bayesian P-splines. J Comput Graph Stat. 2004 Mar 1; 13(1):183-212.

16. Brezger A, Lang S. Generalized structured additive regression based on Bayesian P-splines. Comput Stat Data Analysis. 2006 Feb 24;50(4):967-91.

17. Fahrmeir $L$, Kneib T. Propriety of posteriors in structured additive regression models: theory and empirical evidence. J Stat Planning Inference. 2009 Mar 1;139(3):843-59.

18. Kammann EE, Wand MP. Geoadditive models. J R Stat Soc: Ser C: Appl Stat. 2003 Jan;52(1):1-8

19. Yahya WB, Adebayo SB. Multilevel ordinal response modeling of trend of breastfeeding initiation. Am J Biostatistics. 2013 Jan 1;3(1):1.

20. Khatab K, Fahrmeir L. Analysis of childhood morbidity with geoadditive probit and latent variable model: a case study for Egypt. Am J Trop Med Hygiene. 2009 Jul 1;81(1):116-28.

21. Adegboye OA, Kotze D, Adegboye OA. Multi-year trend analysis of childhood immunization uptake and coverage in Nigeria. J Biosoc Sci. 2014 Mar;46(2):225-39.

\section{Publisher's Note}

Springer Nature remains neutral with regard to jurisdictional claims in published maps and institutional affiliations.
Ready to submit your research? Choose BMC and benefit from:

- fast, convenient online submission

- thorough peer review by experienced researchers in your field

- rapid publication on acceptance

- support for research data, including large and complex data types

- gold Open Access which fosters wider collaboration and increased citations

- maximum visibility for your research: over $100 \mathrm{M}$ website views per year

At BMC, research is always in progress.

Learn more biomedcentral.com/submissions 